\title{
On the Reform and Practice of College English Translation Teaching from the Perspective of Translation Workshop
}

\author{
Hongchun Deng \\ (Jingdezhen Ceramic Institute, Jingdezhen 333403, China)
}

Keywords: Translation workshop; Translation teaching; Reform; Practice

\begin{abstract}
The traditional translation teaching mode has many limitations such as more emphases on theory than on practice, the lack of students' initiatives and creativity, the simplistic evaluation system. Translation workshop, which redefines the roles of teacher and students and pays attention to the combination of translation theory and practice as well as the whole process of translating, can be effectively applied to college English translation teaching, thus fostering knowledge-exploring ability and team-work awareness, enhancing professional translation qualification and proficiency.
\end{abstract}

\section{Introduction}

It is clearly demonstrated in Course Teaching Requirement for College English that, the aim of college English teaching is to foster students' comprehensive ability to listen, speak, read, write and translate in English. This comprehensive ability will be manifested by means of translation in the end, because translation involves both receptive and productive abilities, meanwhile requiring translators to understand and apply two languages and cultures. In terms of teaching objectives, the development of translation competence is very necessary for non-English majors. Globalized economy has an increasing demand on tranlation talents, especially translation talents in science and technology, and these talents are mainly from non-English majors with professional backgrounds. The limited number of English major graduates can no longer meet the social demand on translation talents. However, the present college English translation teaching has many limitations and students' translation proficiency is far from satisfactory. Therefore, it is imperative to reform the traditional college English translation teaching, and in this respect "translation workshop" can provide us with a beneficial teaching perspective.

\section{Limitations of Traditional College English Translation Teaching Mode and the Necessity of Reforming It}

Since the reform and opening to the outside world in 1978, English education has earned great emphasis in China and college English has been ranked as a required course for college students. However, after many years of teaching, college English translation teaching has engendered many disadvantages: 1) More emphases on theory than on practice, more attention to literary translation than to pragmatic translation to be detached from social demands. The traditional translation teaching spares most of time to explain some translation theories with more emphases on literary translation, and the translation theories mainly involve the methods and evaluation criteria of literary translation, such as literal translation and liberal translation, domestication and foreignization, functional equivalence and "faithfulness, smoothness and elegance" and so on. However, pragmatic translation, like scientific and technological and tourist materials which are closely related to our social and economic development, is seldom concerned, and what is more, the common phenomena and laws of variation in tranlation of pragmatic materaials are not explained and discussed. Consequently, students will have great difficulty in undertaking pragmatic translation; 2) The dominant position of teachers and the lack of students' self-study abilities and creativity. In the traditional translation class, the teacher is in a dominant position to determine the will-be-adopted textbooks and tranlation theories and translation practices, while the students are passive and short of participative awareness and sense of accomplishment. Consequently, the translation class is lifeless and boring; 3) More emphases on error correction and a simplistic 
evaluation system. The traditional translation teaching pays great attention to the end-product of translation ---students' translated versions, and the teacher will spend a great deal of time correcting students' translation errors. Besides, the teacher does not provide proper supervision of the translation process to students and ignores the efforts and progress they have made in the translation process. As a result, students tend to feel greatly frustrated when they are faced with the so-called authoritative translation version and are afraid of tranlation class with little interest.

Based on the above analysis, it is obvious that the social and economic development and the unguent demand for translation talents has made it imperative to reform the traditional college English translation teaching. It is a must to abandon placing too much emphases on theory and less emphases on practice. In addition to necessary literary translation theories and practice, it is more urgent to adhere to the social needs to conduct pragmatic translation. What is more, we should redefine the roles of teachers and students, encourage students to make more efforts to participate in the translating process and evaluate students' translation from multiple angles. All these can be addressed properly in the "translation workshop" teaching mode.

\section{College English Translation Teaching in a Translation Workshop Mode}

\section{Definition of Translation Workshop}

A workshop refers to a particular group of people who undertake a creative project or conduct an investigation or research concerning a specific topic. The paricipants of the workshop gather to discuss questions and share experience or knowledge in order to solve practical problems. A workshop can be a brief and intense course, a professional seminar or a series of conferences. If we introduce a workshop to a translation classroom, then a new translation teaching mode---translation workshop---will come into being, which puts a great importance on a lot of translation practices. Prof. Li Ming and Zhong Weihe, veteran teachers in translation workshop teaching, define "translation workshop" as follows: a translation workshop is an activity in which a group of translators gather to make a heated discussion on specific translation tasks, express respective ideas, and produce a universally accepted translation among all members in the end. ${ }^{[1]}$ As a new teaching mode, translation worship does not put translation theories on the primary position. Instead, it combines translation theories with translation practices, adopts group discussions and cooperation, and makes students experience the whole translating process so as to understand the essence of translation and learn how to conduct translation by means of cooperation with others.

\section{Redefinition of Teachers and Students in a Translation Workshop Teaching Mode}

Translation workshop is an innovation against the traditional translation teaching and redefines the roles of teachers and students, which means that offering fish to people has been turned into teaching people fishing. Therefore, the translation classroom is becoming active and energetic.

In traditional translation classroom, the teacher is the dominator who spares a lot of time explaining some abstract translation theories and skills and proceeds to ask students to do translation exercises in the textbook or prepared beforehand. Later the teacher offers the so-called translation and correct the mistakes in students' translation, and the whole translation class comes to an end. As it can be seen, the teacher serves a knowledge-carrier, right-answer-provider, evaluator of students' translation. Because of lack of the teacher's communication with and guidance to students and participation in the process of students' tranlating, the translation classroom has become the teacher's monologue and monodrama.

After the introduction of translation workshop to translation teaching, the teacher is no longer the dominator of the classroon and proceeds to play many roles. Firstly, the teacher is an organizor and coordinator of the classroom. He will divide students into different translation workshops according to their English proficiency and characters, and then make sure that all members of workshops must cooperate well and try their best through an effective coordination. Secondly, the teacher is an creator and supervisor. He will create many opportunities and ways to help members of workshops better understand the materials to conduct effective translation, and provide a postive and harmonious atmosphere to get rid of laziness and slackness. Thirdly, the teacher is a guide and coach. He will provide constructive guidance to students in material understanding, group 
discussion, collective translation and translation correction by means of his professional translation knowledge and qualifications. He will also adopt various methods to evaluate students' translation, timely find out and point out their errors and problems, and stimulate them to think and coordinate for a solution. Finally, the teacher must be a diligent learner and practioner in the translation field. Translation is a translingual and transcultural comprehensive discipline, so a qualified translation teacher must boast solid foundation of translation theories, extensively acquire knowledge of foreign liguistics and applied linguistics as well as other fields, and accumulate practical translation experience through undertaking translation projects.

In traditional translation classroom, students are passive receivers and short of rational understanding of translation theories and skills explained by the teacher without rights to choose or suggest the materials to translate. While translating, they do it separately without communication with fellow students and the teacher. What is more, when students study the reference translation, they do not know why they made mistakes and tend to suffer from frustration, which will lead to lack of interest in translation studies.

In the teaching mode of translation workshop, the roles of students has changed a lot. Firstly, students will become the center of the classroom, a passive receiver turning into an active participant. Students will get involved in and experience the whole translating process, including the selecting and understanding of materials, adopting translation strategies, finding and determining terms, forming and correcting translation. Secondly, students are active cooperators in a team. In order to make the team hand in a satisfactory translation, each member must learn to communicate and consult with others, offering advice and contribute talents. Thirdly, students are knowlege explorers and constructors. Through experiencing the translating process, they will gradually acquire the knowledge for translation and turn it into their reservoire to lay a sound foundation for the future translation work.

\section{Procedures of Translation Workshop Teaching Mode}

Translation workshop teaching mode has its distinctive features and feasibility, and it can go with the following phrases:

\section{Pre-Translation Phrase}

In the pre-translation phrase, the teacher explains some relevant translation theories. Before the class, the teacher chooses translation materials according to students' linguistic proficiency and interests as well as suggestions. The translation materials can fall into different categories, with a majority of scientific and tourist materials and a moderate number of literary ones, posted in the public E-mail box for students to download. At the beginning of the class, the teacher spares 20 minutes to explain necessary translation theories and skills, and then makes a brief interpretation of the textual features and the translation methods of the materials in order to prepare for the following translation practice. Translation workshop pays great attention to fostering practical skills to solve translation problems, but it does not ignore translation theory teaching ${ }^{[2]}$, so proper theory teaching is imperative.

\section{Translation Phrase}

The translation phrase involves students' understanding of the original materials and expression of the translated version. After the students has got the materials, the teacher asks some key questions to help them get the essence of the passage. Meanwhile, students are encouraged to underline those difficult-to-understand points and reach agreement in understanding them after group discussions. Then students adopt specific translation strategies according to the textual features of materials, target readers, translaion purposes. In the expressing phrase, students can refer to dictionaries to establish bilingual term corpus, or serch for parallel corpuses through internet and library sources. After group consultation, an elegant and readable translation can be obtained.

\section{Post-Translation Phrase}

Post-translation phrase involves the correction and evaluation of the translation offered by each workshop. Ather finishing the translation, workshops can carry out correcting translation mutually, underlining the well-translated parts with wave lines and the defective ones with red lines for emphasis with suggestions to correct. After correcting the translation, the leaders of different 
workshops demonstrate their respective corrected translation to the whole class and make presentations about understanding materials, determining translation strategies and dealing with specific sentences and expressions. Then other students can raise questions about the corrected translation or point out improper points. During the process, the teacher must make appropriate comments on the translation and point out its merits and imperfection with constructive suggestions. In the end, the teacher and students get together to summarize the relevant translation strategies and skills so as to make students understand the laws and essence of translation and learn to translate eventually.

\section{The Significance of Translation Workshop Teaching Mode for Training Talents}

Translation workshop teaching is based on the idea that translation competence is not taught but acquired through practice, thus it introduces translation practice to the classroom ${ }^{[3]}$. As a result, the traditional translation teaching mode under which translation theories are overemphasized and detached from translation practice is reformed. What is more, the teacher-centered and forced-feeding classroom is transformed into a student-centered, explorative and collaborative one, fostering students' abilities to find and solve problems, to express themselves, and cooperate with workshop members. More importantly, to choose pragmatic materials closely related to the social and economic development and do a lot of translation practice can make translation talents, who can adjust to the market demand instead of being limited to literary translation. Translation workshop teaching pays attention to the whole process of translating and enables students to gain an insight of the translation essence. In addition, it can develop students' sense of responsibility and arouse their infinite enthusiam in translation career, preparing them for qualified translation talents.

\section{Summary}

The traditional translation teaching mode has many dismerits and can not meet the demands on translation talents for modern economic and social development, thus in badly need of reform. The introduction of translation workshop to the translation classroom is a bold innovation to the traditional translation teaching mode. Because it can stimulate students' thirst for knowledge, foster their explorative ability and teamwork spirit as well as professional translation proficiency, translation workshop teaching mode is worthy of recommendation in college translation teaching.

\section{References}

[1] M. Li, W.L. Zhong. On Translation Workshop Teaching[J]. Chinese Translators Journal, 2010(4): 32.

[2] H. Xiao. On the Application of Translation Workshop to Translation Teaching[J]. Journal of Sichuan International Studies University, 2005(1): 139.

[3] H.P. Liu. On Principles and Methods of Undergraduate Translation Teaching[J]. Chinese Translators Journal, 2009(6): 45-46. 